onset of porphyrinuria was expected to be quicker. Group 1 showed no change in urinary porphyrin, but Groups 2 and 3 showed extensive porphyrinuria following two injections of 400 and $600 \mathrm{mgm}$. T.N.T. per $\mathrm{kgm}$. respectively $(1.9 \mu \mathrm{gm}$. to $6 \cdot 3 \mu \mathrm{gm}$., and $5.4 \mu \mathrm{gm}$. to $15.5 \mu \mathrm{gm}$.). The acid shakings of the urines of these two groups were dark brown. The modified Webster's test was again negative throughout, and the control group showed no change in porphyrin output.

The results show that the absorption of T.N.T. in the rat takes place more rapidly in the stomach than by subcutaneous injection; the toxic effects such as porphyrinuria and liver damage follow more quickly. A red urine was not produced by administering doses of $2: 4$-dinitrotoluene or of $p$-nitrotoluene, and it is suggested that three nitro-groups are necessary for the formation of the red colour.

G. F. SOMERS.

G. B. WEST.

College of the Pharmaceutical Society, London, W.C.1.

${ }^{1}$ Channon, Mills and Williams, Biochem. J., 38, 70 (1944).

West, Quart. J. Pharm., 14, 26 (1941).

Ingham, Lancet, 554 (Nov. 8, 1941).

- Rimington and Hemmings, Lancet, 1, 770 (1938).

- Kennedy and Ingham, Brit. Med. J., 1, 490 (1942).

\section{Birds and Butterflies}

CAPT. C. R. Stonor, under this heading in Nature of July 15, p. 80 , says that he "did not see a single bird, of any species, eatch or chase a butterfly" during a month in rain-forest in South India. One can only comment that abundant evidence was provided from tropical Africa by the late C. F. M. Swynnerton. This outstanding field naturalist, well known for his work on tsetse control, could not find time, while engaged in this work, to sort out the massed observations for publication. After his lamented death in an aeroplane crash, it fell to my lot to edit some of his material ${ }^{1}$.

It is interesting to note that some of the subjects of these records were the same families-or even genera-of birds as were seen by Capt. Stonor not catching butterflies; for example, rollers, bee-eaters, drongos. Capt Stonor especially mentions the "large racquet-tailed drongo" in his negative evidence, and I would refer him, and readers, to my note ${ }^{2}$ in which I showed photographs of two butterflies from different parts of the range of this bird, each bearing a clearly imprinted mark on a wing closely corresponding with the imprint of the bill of a specimen.

Not only does the study of such beak-marks provide evidence that butterflies are attacked but also, as $I$ showed in $1941^{3}$, it has provided significant evidence that the attacks are less destructive of the aposematic ('warningly coloured') species which serve as models for mimicry than those mimicking them. Regarding Capt. Stonor's statement that he saw no beak marks, I may perhaps be excused for saying that they are not always so obvious as those I have mentioned above, and particularly in "tattered specimens" which have been mauled and rubbed so that the density of the scaly covering is reduced; experience in close study of 'set' specimens is needed.

The statement that "the butterflies seldom flew higher than four or five yards from the ground; while most of the insectivorous birds ... feed twenty feet up at the least", presumably means that it is considered that at high levels there are no butterflies to be attacked. This, however, is far from being the case. It is recorded by Beebe ${ }^{4}$, Hingston ${ }^{8}$ and Chapin ${ }^{6}$ that the fauna of the tree-tops is distinct from that at lower levels, and Hingston particularly notes "Butterflies are commonly seen fluttering over the canopy. Some species probably never come to earth." Most butterfly collectors in the forests must have had my exasperating experience of seeing desirable specimens flying around and settling on the tops of trees in flower. The oriental butterfly Eriboea schreiberi Godt. is particularly interesting in this connexion. It is stated by Fruhstorfer' to be 'extremely rare' (that is, in collections) and he also says "It is also frequently stated that single wings are found from which we may conclude that schreiberi is very much pursued by birds". The same curious fact is the subject of comment by Poulton in his notes attached to G. A. K. Marshall's records of attacks on butterflies ${ }^{8}$.

Department of Entomology, G. D. Hale Carpenter. University Museum, Oxford.

1 Proc. Linn. Soc, Lond., Session 1941-42, Part 1, 1 (1942). 2 Carpenter, G. D. Hale, Proc. Roy. Ent. Soc. Lond., A, 18, 25, Pl. 1 (1943).

'Carpenter, G. D. Hale, Proc. Zool. Soc. Lond., A, 111, 223 (1941).

"Beebe, C. W., "Tropical Wild Life in British Guiana" (New York, 1917), 81 .

"Hingston, R. W. G., "A Naturalist in the Guiana Forest" (London, 1932), pp. 62, 350, 353-354.

"Chapin, J. P., "The Birds of the Belgian Congo", Bull. Amer. Mus. Nat. Hist., 65, 224 (1932).

7 "The Macrolepidoptera of the World". Edited by A. Seitz. IX. The Rhopalocera of the Indo-Australian Faunal Region (Stuttgart, 1908), 725.

Marshall, G. A. K., Trans. Ent. Soc. Lond., 365 (1902).

\section{A New Species of Amœba: A. kerrii}

SrNCE the publication of full details with relevant plates and drawings will necessarily be long delayed, the following account of a new species of amoaba belonging to Schaeffer's genus Metachaos, isolated from some water-weeds collected on the shore in front of the Marine Biological Station of Keppel by Miss Maureen McAlister in 1939, and now under cultivation in Notre Dame Laboratory, will serve as a preliminary notice to other workers.

Species of the genera Chaos and Metachaos are distinguished by their cytoplasmic characteristics or by details of their life-history. This amœba, named in honour of Sir John Graham Kerr, who first emphasized the urgent necessity of research on an organism so universally used for education in biology, is easily identified in its fully adult and senile stages by its dusky appearance when viewed over a black background by reflected light, this dark colour being due to the extraordinary abundance of crystals which distend the cytoplasm and completely mask the presence of the nutritive spheres. The nucleus by contrast looks almost like a vacuole as it is rolled about in the cytoplasm.

Young adults and adolescents are much clearer and more like the typical appearance of most of the freeliving, large amœar. Pure-line cultures of $A m œ b a$ kerrii are easily established, the creature feeding on rotifers, ciliates and flagellates. Wheat grains form a suitable pabulum.

Fission divisions occur in adolescent and in young adults, but not in old or senile adults, once in three 